\title{
Manifestation of Culture in Traditional Architecture of Iranian House Based on Old Houses in Kashan
}

\author{
Hamidreza Farshchi ${ }^{1}$, Fariborz Sediqi Arfaei ${ }^{2}$, Vahid Askari Kashan ${ }^{3} \&$ Fatemeh Jamali ${ }^{4}$ \\ ${ }^{1}$ PHD student at Shahid Beheshti University (SBU) and faculty member in Architecture Department of Kashan \\ University, Kashan, Iran \\ ${ }^{2}$ Assistant Professor and Faculty Member in Humanities Department of Kashan University, Kashan, Iran \\ ${ }^{3}$ MA student of Architecture Department of Kashan University, Kashan, Iran \\ ${ }^{4}$ BA student of English Literature Department of Tehran Al-Zahra University, Tehran, Iran \\ Correspondence: Hamidreza Farshchi, PHD student at Shahid Beheshti University (SBU) and faculty member in \\ Architecture Department of Kashan University, Kashan, Iran. Tel: 98-91-3161-7591. E-mail: \\ farshchi46@kashanu.ac.ir
}

Received: October 10, 2015

Accepted: December 12, 2015

Online Published: January 24, 2016

doi:10.5539/mas.v10n2p185

URL: http://dx.doi.org/10.5539/mas.v10n2p185

\begin{abstract}
Culture has huge effect on designing architecture form and space and also on quality of resident lives. Architecture applied in the places should be based on recognition of resident culture so as to satisfy their mental and physical needs, otherwise they would not be able to communicate with the space and feel pleasant sense of belonging. Although most designers focus on significance and influence of culture on building, they simply ignore the essence of culture and its impact on designs. In this research, in order to recognize how Islamic Iranian culture components manifest in the body of traditional house architecture, old houses in Kashan by using case study and descriptive and analytical method are studied. Considering culture elements including values, national norms and customs, myths and religious beliefs, spatial hierarchy, internal and external consistency, privacy, and communication with the nature and type of planning as the main criteria, this conclusion can be drawn that despite of all functional and regional limitations, architects pay adequate attention to resident culture and its impact on the deepest layers of their mind. Such researches are truly essential to survive contemporary housing pattern which is constantly falling into decline under the municipal laws.
\end{abstract}

Keywords: old houses, Islamic Iranian culture, traditional culture

\section{Introduction}

A new concept of culture came to exist when realization of life and human behavior became necessary. Since human behavior in life cannot be limited merely into biological wants and mechanisms such as the requirement for shelter and it may take complicated shapes in relation to values, goals, expectations, ethics, customs, and traditions (Rapoport, 2005).

Iranian historical architecture is a stable pattern in which there is no border between design ideas and cultural issues- in other words, like salt in food, culture is embedded in this type of architecture (Ashouri, 2002).

In recent decades, with alteration of lifestyle that almost encompasses all religious, political, social, and economical aspects, culture has been changed as well. Consequently, housing design also is just concentrated on quantitative dimensions while qualitative aspects are carelessly ignored (Rapoport, 1969).

In order to understand the meaning lying in cultural design, it is essential how to discipline behavioral setting in residential areas -that is, life style can play significant role in discovering methods to utilize spaces in accordance with culture. This study helps to find out the cultural meaning emerged in architecture of traditional houses in Kashan by benefiting from case study method.

\section{Meaning of Culture}

Culture includes all the material and spiritual motives in which a person can live and grow and it gives her or him cultural identity. In this way, it affects human behavioral tendencies, in other word, dwelling in specific cultural spaces gives human certain values, makes moral norms deeply embedded in her or his nature, and forms 
human moral structure. The whole thing in psychology called individual and group consciousness and unconsciousness is also rising out of culture (Ashouri, 2002).

Culture is an idea and theoretical structure and as well as a feature for many topics such as human thoughts, beliefs, and practices (Ashouri, 2002).

\section{Culture Influence on Environment}

Environment may generally be considered as an educational tool which can mentally be reminder of correct behavior. If this viewpoint indicating environment one way or another has relation with culture and functions as indicators of culture is acceptable, then environment role in establishing culture will rationally be followed (Pourdeyhimi, 2010).

In sum, human being behavior embraces interaction and relations effected by the rules and situations that are constantly in touch with the environment elements. Realizing the relation between these concepts is part of establishing and adopting culture. The truth is that all of us behave according to mentioned relations, however, clearly some people are more affected than others.

\section{Culture Influence on Design}

In most cases, resident culture disagrees with designers. Cultural differences and contradictions resulted from various interpretation and definition of environment and its internal behavior can raise many problems for residents. So in any circumstance, environment and its internal behavior should be well defined and analyzed (Pourdeyhimi, 2010).

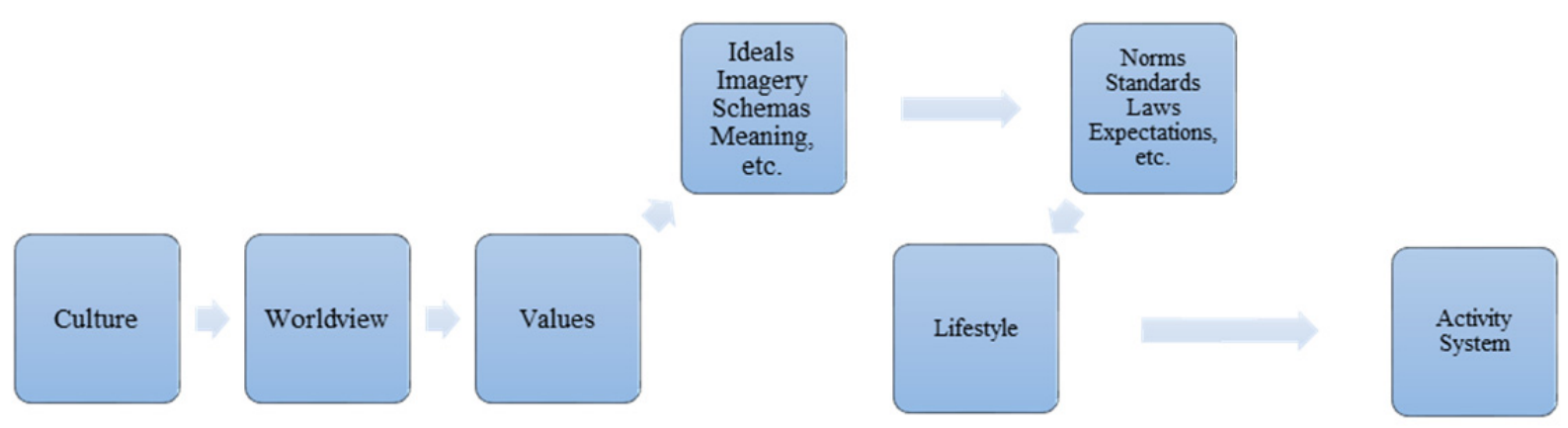

Figure 1. Analyze culture to its holistic nature

\section{Definition of House}

The perspective and viewpoints of various society toward house are diverse. In some period, it is regarded as a machine for living in (Le Corbusier), or as the place in which all veils has completely gone (Mies van der Rohe). In another period, it is introduced as more dwelling place and residents are represented as mortal creature living on the earth and under the sky (Martin Heidegger). He criticizes modern architecture theories which attribute house to a machine or tool and restrict the profound concept of dwelling into merely consumer relation uni (Kiani, 2002). In another view, house plays a role of a center with multi-visual abilities. "In the first place, house as a cultural center is built for complicated purposes", says Rappaport (Lawrence, 1995). House shape and spatial organization is strongly influenced by the culture to which it belongs, even in the past that house functioned as a simple shelter for primitive humans, its meaning was not summarized into only functional benefits. Although its role as the shelter was highly substantial, its positive aspect of making pleasant place as a social unity was considered more valuable.

The concept of house as a material does not reveal in terms of interior space organization, rather in designing. In everyday life, the meaning of house dwells among the place functions. Places possess meanings and the house is the main place wherein humans spend their much time and make common life interactions (Saunders, 1990).

\section{Culture Influence on House Design}

Human settlement is one of the most important factors that forms societies and nations. The settlement quality and quantity of various communities make variety of cultures which gradually turn into part of the communities.

Culture serves as a highly vital factor in designing buildings. A house which does not meet cultural requirements in spatial divisions is not regarded as the proper place. In such cases, residents may soon make some changes in 
the house plan. Hence, architect should be quite aware of the culture and customs of people in order to create satisfying place for residents. For instance, having separate spaces for different sexes and ages or public and private spaces in the house are useful to fulfil cultural necessities (Masaeli, 2009).

The concept of culture is too challenging to be defined, but three elements of culture are generally mentioned: lifestyle, human mental aspects and habits, and adjustment to various environments. The aim of attention to culture in lifestyle is to provide better conditions for life. The second element basically deals with monitoring all the factors of lifestyle. Adjustment to distinct environments, is another element of culture which specifies different social groups. The reason of separation of social groups is to designate the difference among them. Thus, in combination of diverse aspects of culture, it is easily clear that the key focus circles around the people individual and group lifestyle.
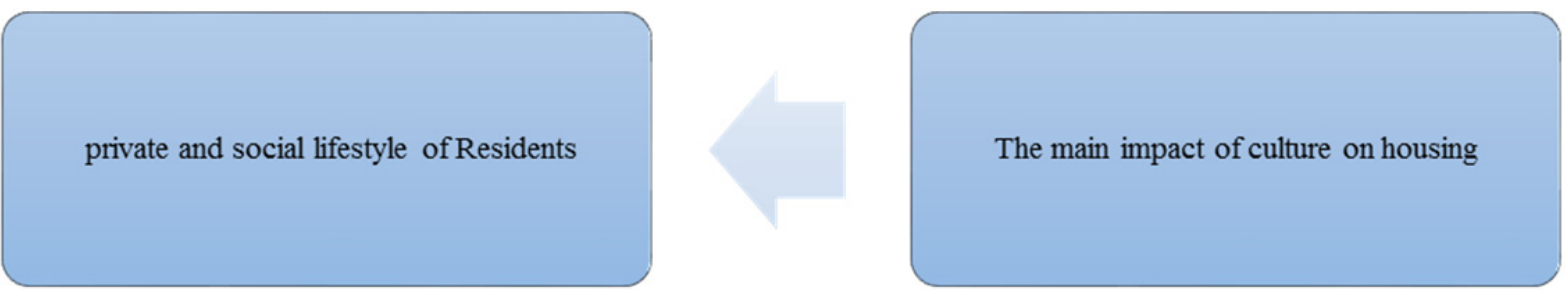

Figure 2. Culture and Housing

In some spaces, despite of having functions in common, their standards and rules may be discriminated from each other due to different resident lifestyles. For example, light level, sound, temperature, size, type and the shape of the stairs, the residential density, and establishment of identity in residential and work areas vary from place to place (Rapoport, 2005). Research shows that in United States of America light level is sixteen to twenty times more than Finland's and Sweden's. In another study, residential density in Hong Kong is estimated fourteen to fifteen times more than USA's. In fact, the residential density in a cultural context may differentiate from the others. In residential areas, culture has important role in determining density and open spaces (Rapoport, 2005).

Culture can also play different roles through diverse mechanisms. Willingness or unwillingness to socialize and interact with relatives or with strangers depends on social culture. Moreover, the type of private places, discipline, and the way of behaviors, manners and interactions in the places are at variance from one culture to another.

For example, overlooking level resulted from high density and population hinges on diverse definitions and tricks for preventing overlooking. Thus, designers should recognize and pay attention to the first priority of residents. In general, resident priorities are originated from their physical environment improvement which itself drastically relies on their cultural values.

The priorities of the buildings with different functions vary from each other. Some of the priorities embrace territory, hierarchy, security, privacy, flexibility, audibleness, convenience, economy, energy efficiency, communication, interaction, mental image, maintenance, personal spaces, safety, cleanliness, and the sense of dynamics (Memarian, 1996).

Finally, this conclusion can be drawn that in house design, culture is more valuable to notice than building functional aspects, since house is not just a machine or tool (Chaney, 1996).

\section{Iranian Traditional Housing}

Iranian house not only functions as their shelter and safe place, but also means a world to them wherein they grow, learn, and pray. The architecture creating Iranian old house imagines the final plan of the building at the beginning of designing. The architect designs part by part of the plan and set artfully every section of the house in its exact place (Haeri Mazandarani, 2002). Therefore, the cultural and divine values manifest perfectly in every corner of the house.

Traditional residential texture of Iran reflects architecture goal - that is, make an ideal area, consequently, it has symbolic values rising out of social culture factors. These major social factors have dramatically effect on housing of residential areas. 


\section{Iranian Culture Influence on Traditional Housing}

\subsection{Hierarchy}

Because of its role in making privacy and relation between public and private parts of the house, hierarchy is considered as one of the magnificent social factors in housing. In relation to housing, it can be defined into two internal and external level. External hierarchy embraces house internal section relations with the others, while internal hierarchy emphasizes relation of house internal places with each other. It is worth noting that the importance of hierarchy in internal relations is not less than house external relations.

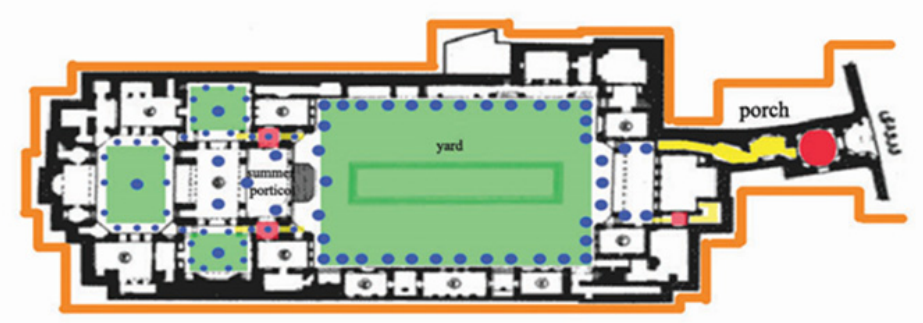

Figure 3. Hierarchy in Broujrdiha House in Kashan

\subsection{External and Internal Relations}

Introspection presence in Iranian houses has profound meaning which brings external spaces inside of the house -that is, the coexistence between inside and outside occurs in the house. Unlike to western architecture in which an object is regarded as positive element, Iranian architect emphasis is centered on the place to enable residents to focus and find their own being (Memarian, 1996).

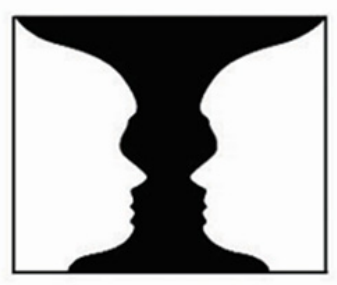

Modern Architecture

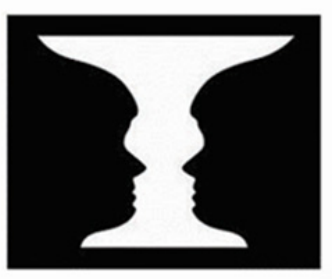

Iran Traditional Architecture

Figure 4. The comparison of space and mass in modern and traditional Iranian architecture

These two spiritual and material characteristics are the reasons for survival of the culture and art in this region. As a result, in Iranian traditional houses, introspection principal and privacy emerge successfully through using different elements such as yard, porch, corridor, reticulated windows opening toward the central yard. A tendency to protect house privacy and have no visual relation with urban spaces outside of the house, make house spaces attractive, separate day and night sections, and manage space by using yard, in a word introspection with an emphasis on maximum confidentiality and privacy are the housing basic features of Iranian traditional houses. 


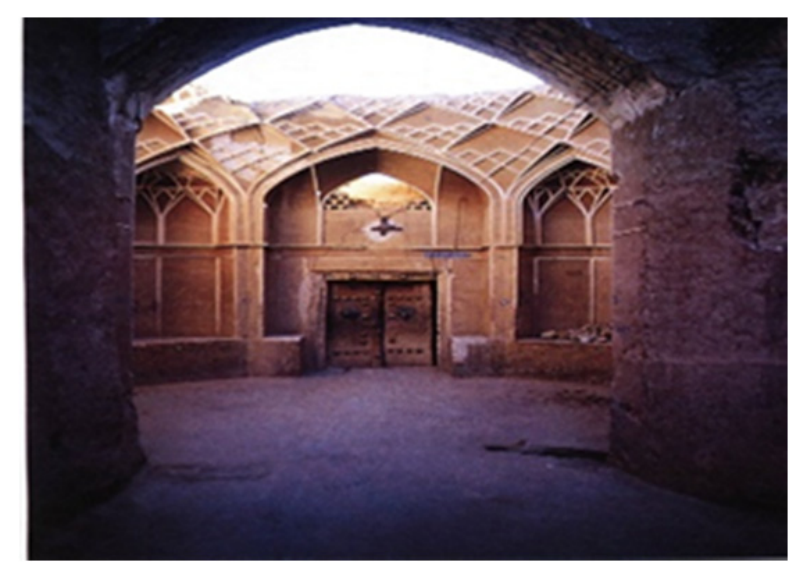

Figure 5. Abbasian house porch in Kashan

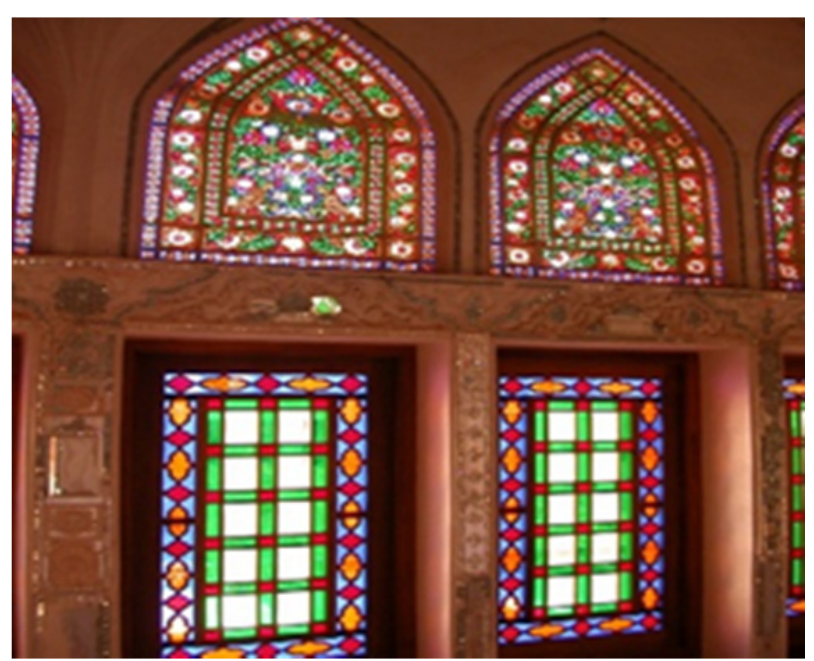

Figure 6. Abbasian house reticulated windows in Kashan

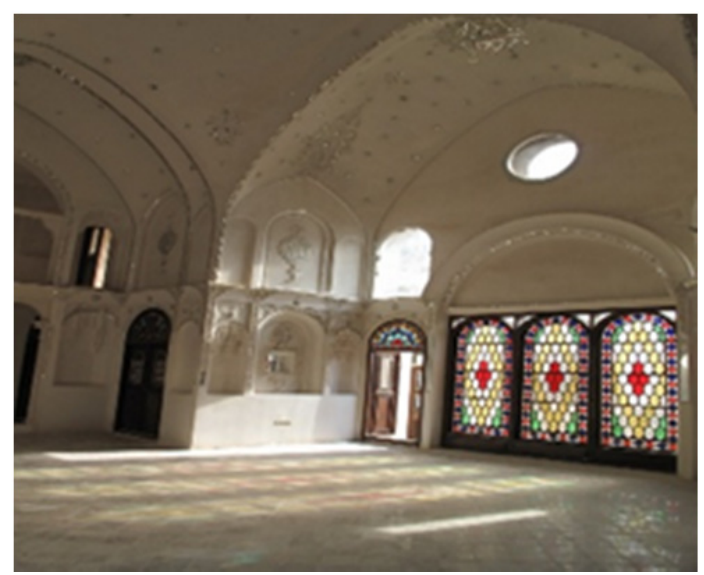

Figure 7. Brougerdi house reticulated sash in Kashan

Another characteristic of privacy involves in organizing appropriate internal space relations so that not only keeps internal spaces out of stranger sights, but also sorts family territories (parents and children, female, and male) from each other (Naghizade, 2000). 


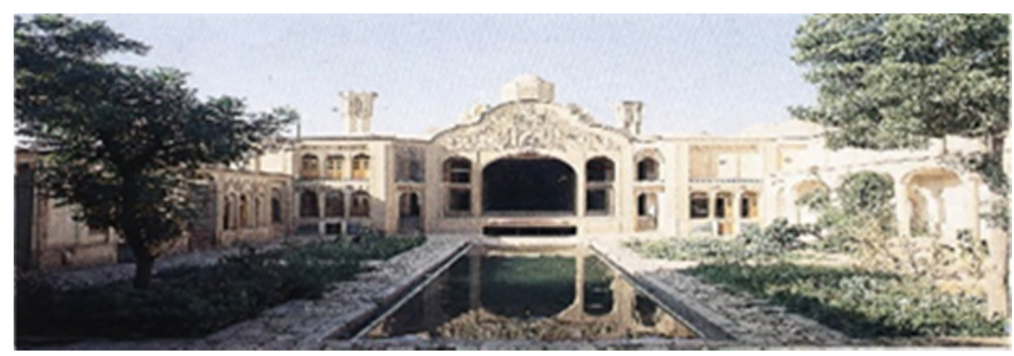

Figure 8 . Tabatabaee house yard makes introspection and discipline in the space

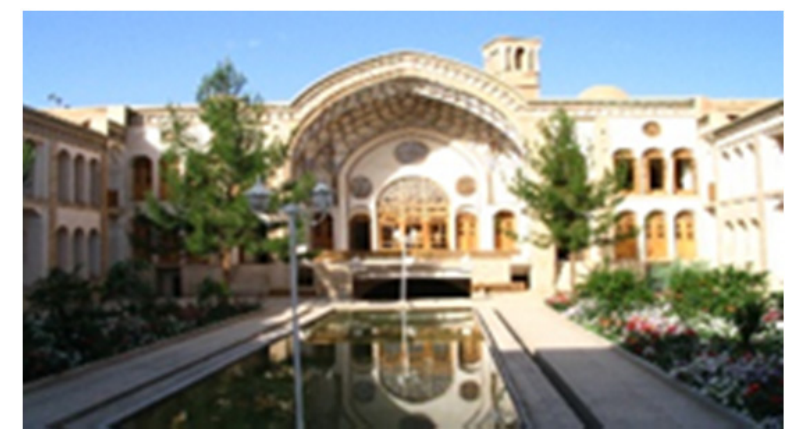

Figure 9. Ameri house yard

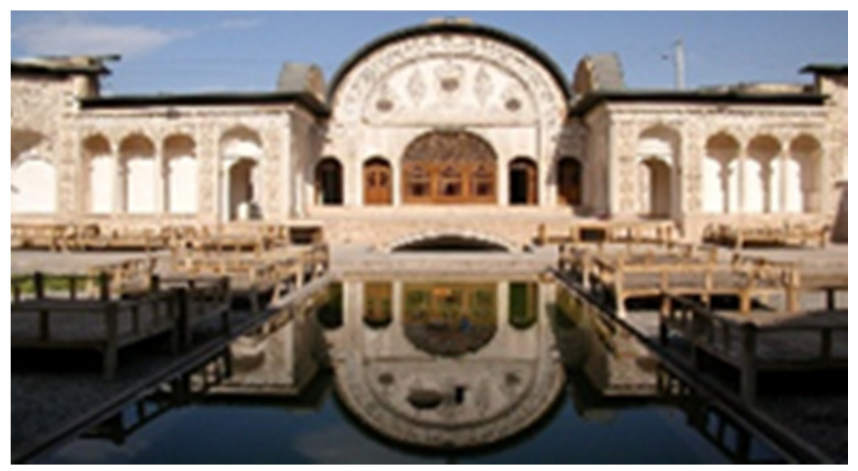

Figure 10. Broujerdi house yard

\section{Movement, Discovery and Witness}

Iranian house cannot be seen with one sight. Organized spaces are not visible from the entrance, rather accessible from public to private places consecutively (Haeri Mazandarani, 2002). In addition, it is obvious that having regard for family privacy penetrates deeply into Iranian architect minds, so their designs turn privacy which holds its roots from Islamic Iranian culture into one of the most fundamental principal of residential architecture.

\section{Privacy and Territory}

House is considered as a cultural private place which separates us from each other, yet reflects coexistence with others. Privacy and individuality are both cultural concepts which vary from one culture to another. Societies in which individuality and individual-oriented values prevail, privacy in terms of both spatial and social meaning is one of the vital concepts of social life. In such cultures, house architecture is arranged so that each family member can have her or his own privacy. 


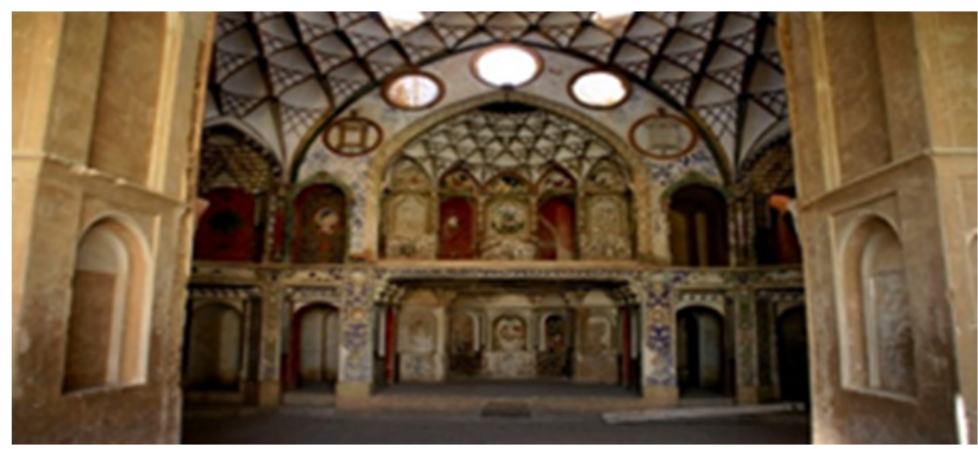

Figure 11. Floating micro-space in the private space

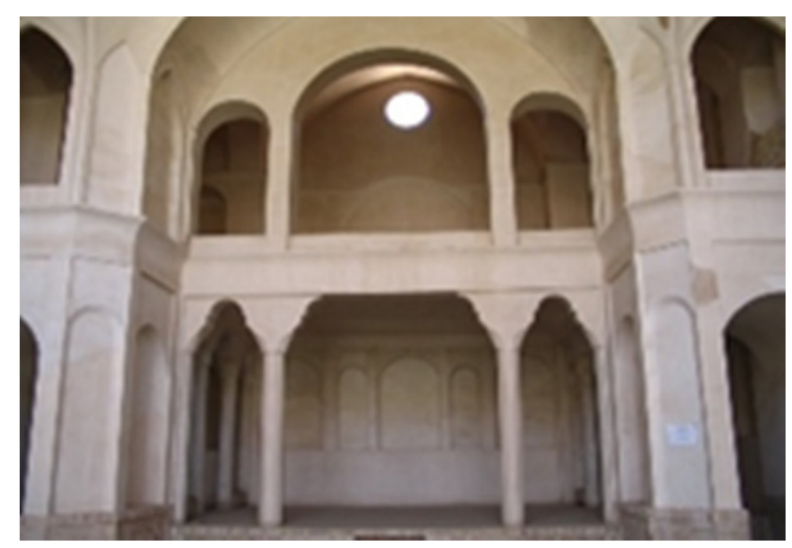

Figure 12. Ameriha house micro-space in the private space

\section{Revolution of Housing Culture}

Urbanization development occurred as a result of industrial revolution has been speeding up rapidly. Modernity developments and its effects on human settlement pattern not only deals with quantitative dimension of population increase and consequently growth of need for house and settlement, but also creates different social housing pattern for human.

The first wave of modern architecture encompassing features such as smallness, simplicity, maximum use of space, lack of sign and color, and spatial function division has been regarded as turning point in housing culture patterns so far.

\section{Modernity Processes on Housing Culture}

1. Rationalizing and modernizing house: It chiefly involves in running away from traditionalism and proceeding toward modernity.

2. Urbanizing house: Modernity often comes with secularization of house. With improvement of modernity, metaphysical and spiritual aspects of house dominating diverse dimensions of culture gradually have been replaced by material values.

3. Globalizing house: Expansion of globalization process and the worldwide web progressively have been reducing the importance of house and place and highlighting the significance of cyberspace (Kiani, 2002).

4. Individualizing house: It concerns with superiority of individual demands and desires over social structure requirements.

5. Democratizing house: In economic viewpoint, house is as a means which depends on supply and demand laws.

6. Bureaucratizing house: By growing government role in housing, people are capable of choosing their style and taste just within the house. Bureaucratizing and adherence to certain standards have been changing housing style and its internal relations. 


\section{Revolution of Culture in Iranian Contemporary Housing}

Coinciding with the expansion of one-sided relationship with West and their impact on Iran architecture, the residential houses have been changed so that in many cases, historical and traditional balance between house and culture has vanished. In this new architecture, house based on its new functions serves no longer as a traditional and historical place (Ghasemi, 2005).

Islamic Iranian families easily admit these changes. So, exterior and interior are removed and introspective houses take extrospective shapes. The concept of privacy is transformed and children demand their own special rooms. House symbols and signs are also metamorphosed so that they no longer represent traditional culture.

In 1950-1960, the majority of residents evacuated historical houses located in city centers of Iran. In rapid urbanization process, government interfered in order to provide citizens with houses which were constructed as small as possible with useful life of 25 to 35 years. Such a pattern turned out to become the main basis of housing in Iran.

Contemporary housing design is formed by various approaches all of which are not valuable, since the movement in terms of architectural history of a country is worth noticing that covers not only traditional aspects, but also dynamism and independence. Concerning different architectural approaches and studying several works, three dominant streams of thought and the paradigms in house design in contemporary architecture of Iran can be mentioned:

1. Modernity: Factors such as revolution of social life, country industrialization, cloth and custom alteration, freedom of opinion, and the emergence of new building materials help modernity to develop.

Extrospection is the most distinguished phenomenon in this architectural thought. The phenomenon which is in direct contradiction with introspection of traditional architecture of Iran.

2. Combination of modernity and tradition: The reason of some inconsistencies in city are a cultural problems and contradictions. Zein-al-Din believes that if a proper culture feeds residents, they may be able to take advantage of the technology, otherwise it will be a great calamity.

3. Traditionalism paradigm: In this paradigm, architecture is applied to a cultural action of involving climate condition, basic concepts, and vernacular beliefs in designing and construction. If an architect can consider her or his own and social beliefs into designing according to climate condition in terms of volume, form, and space, then she or he will be regarded as a successful designer or architect.

\section{Conclusion}

Adherence to construction rules and customs in terms of both viewpoint of presenting family social dignity and observing social customs in residential areas is a highly important factor in housing. Construction customs have drastic influence on using public places, determining property ownership, building orientation, and access hierarchy with respect to building dignity and privacy in metropolitan areas. Architects and planners who are relatively familiar with behavioral analysis should pay adequate attention to meaning as a product of environment perception, since in many cases, there is a wrong perception of between function and meaning. Meaning not only deals with function and behavior, but also plays the most substantial qualitative role, because certain condition of behavioral system results in special behavioral setting and subsequently creates distinct environment based on the relationship between culture and environment. Hence, lifestyle and behavioral systems are both similarly effective in analyzing the environment.

House as the most fundamental man-made environment is a response to one of the basic daily needs -that is, shelter (Zukin, 1995). Considering house as a private space and property not only highlights its importance as a shelter, but also connects it with psychological concepts having roots in human soul. Todays, being busy with issues such as mass production and housing economy which are the result of modern architecture, make us ignorant of the real concept of house. In order to gain economic profit, houses are built in the shortest time and with the maximum saving in material and consequently, the concept of residence, dignity, and economic values have lost their importance. Pondering characteristic of traditional houses enables us to have a precise understanding of house. By realization of this fact that modernity and its consequences affect our country and even convert Iranian needs, we may become capable of justifying housing changes and attributing compulsory removal of some concepts, spaces, life qualitative principals to the housing alterations. Yet, there are flames of hope that strong points and values of traditional architecture can be well revived in our housing. The same houses built in modern times coinciding with entrance of modernity and its influence on principals of architecture in Iran reflect that at all levels, no absolute imitation of what was or is in the West could penetrate in depth of Iranian architecture and eradicate all its roots. 
As mentioned, three streams of thought and paradigms have been dominant in designing contemporary housing. The entrance and presence of new style in Iranian architecture keeps its main traditional and historical principals and leads old figures to shapes which are in accordance with both modern housing pattern and residential culture.

\section{Reference}

Ashouri, D. (2002). Definition and concept of culture. Second edition. Tehran: Agah publication.

Chaney, D. (1996). Lifestyles: Key Ideas. London: Routledge.

Ghasemi, M. (2005). Introduction to the evolution of contemporary housing. Daneshnama journal, 125.

Haeri Mazandarani, M. R. (2002). Nature Culture House, the historic homes and contemporary standards, to develop a process and criteria for home design. Tehran: Center for Studies and Research Planning and Architecture.

Kiani, M. (2002). The first Pahlavi era architectural transformation of ideas. The emergence and development of architecture of the period twenty years Iran. Tehran: Iranian Contemporary Historical Studies institutions.

Lawrence, R. J. (1995). Deciphering home: An integrative historical perspective. The Home: Words, Interpretations, Meanings, and Environments, 53-68.

Masaeli, S. (2009). Plan acquired as a religious belief in traditional housing Iranian desert. Journal of Fine Arts, $37,27-38$.

Memarian, G. H. (1996). Housing pattern in traditional architecture with introspective approach. Tehran: Elmosanat University.

Naghizade, M. (2000). Qualitative characteristics of good housing design principles and methods of its study. Soffeh Journal, 10(31), 90-103.

Pourdeyhimi, Sh. (2010). Culture and Housing. Journal of Housing and Rural Environment, 30(134), 3-18.

Rapoport, A. (1969). House Form and Culture. CA: Prentice Hall.

Rapoport, A. (2005). Means the built environment: an approach to the non-verbal communication. Translated by Farah Habib. Tehran: Processing and urban planning publication.

Saunders, P. (1990). A Nation of Home Owners. London: Unwin Hyman.

Zukin, S. (1995). Cultures of Cities. Oxford: Blackwell.

\section{Copyrights}

Copyright for this article is retained by the author(s), with first publication rights granted to the journal.

This is an open-access article distributed under the terms and conditions of the Creative Commons Attribution license (http://creativecommons.org/licenses/by/3.0/). 